\title{
EXPERIMENTS ON EGG TRANSFER IN THE COW AND EWE: DEPENDENCE OF CONCEPTION RATE ON THE TRANSFER PROCEDURE AND STAGE OF THE OESTROUS CYCLE
}

\author{
R. A. S. LAWSON, * L. E. A. ROWSON, R. M. MOOR AND H. R. TERVIT $\dagger$ \\ A.R.C. Unit of Reproductive Physiology and Biochemistry, \\ Animal Research Station, Huntingdon Road, Cambridge
}

(Received 19th December 1974)

Summary. The effects on embryo survival of procedures used in transferring eggs non-surgically were investigated in three experiments in ewes and heifers. In Exp. 1, two techniques for introducing eggs into the uterus through the cervix in heifers were compared; namely (i) deposition of the eggs high into the uterine horn or (ii) into the body of the uterus. Both methods were followed by inflation of the uterus with carbon dioxide. Out of a total of 34 heifers, only one became pregnant by the use of Method (i).

Non-surgical egg transfers early (Days 3 to 5) or later (Days 6 to 9) in the oestrous cycles of heifers were carried out in Exp. 2. Three transfer procedures were compared: (i) pipette transfer of an egg into the body of the uterus through the cervix (control), (ii) the control procedure performed under Fluothane anaesthesia, or (iii) followed by inflation of the uterus with carbon dioxide. With transfers carried out early in the cycle, pregnancies resulted in $1 / 10,0 / 10$ and $1 / 10$ of the heifers in the control, carbon dioxide and Fluothane groups, respectively. With late transfers, $7 / 20,1 / 10$ and $8 / 20$ heifers became pregnant in the respective treatment groups. This trend for pregnancy rate to be improved when late transfers were done in the control and Fluothane groups was significant only at the $10 \%$ level of probability when both groups were pooled. It was tentatively concluded, however, that non-surgical transfers of fertilized eggs to heifers may be best done during mid-cycle, after Day 6. Fluothane anaesthesia did not improve conception rate. Inflation of the uterus with carbon dioxide appeared to be deleterious when used at the mid-cycle stage in heifers.

In Exp. 3, it was found that inflation of the ewe's uterus with carbon dioxide or nitrogen following the surgical transfer of an egg did not affect the incidence of pregnancy. The introduction of $50 \mu \mathrm{l}$ liquid Fluothane into the lumen of the uterus was embryotoxic.

* Present address: S. S. Cameron Laboratory, State Research Farm, Werribee, Victoria, Australia.

† Present address: Ruakura Animal Research Station, Hamilton, New Zealand. 


\section{INTRODUCTION}

Development of a non-surgical method for transferring fertilized eggs in cattle would greatly facilitate the application of egg transfer as a technique in cattle breeding. In particular, it could provide a practical means for ensuring the presence of one egg in each uterine horn; this condition appears to result in a high incidence of twin pregnancies in cattle (Rowson et al., 1971).

Attempts to induce pregnancy in cattle by the non-surgical transfer of eggs have, so far, had only limited success (Sugie, 1965; Rowson \& Moor, 1966; Rowson et al., 1969; Vincent et al., 1969). A major difficulty to be overcome is the rapid expulsion of eggs from the uterus which generally follows their deposition in the uterus from a pipette inserted through the cervix (Bennett \& Rowson, 1961; Harper et al., 1961; Rowson et al., 1964). When successful egg transfers through the cervix have been reported, the technique has involved inflation of the uterus with carbon dioxide gas after deposition of the eggs (Rowson \& Moor, 1966; Rowson et al., 1969; Vincent et al., 1969). This procedure appears to reduce the loss of eggs from the uterus although the actual mechanisms involved remain unknown. Conception rates with this technique have been low. Possible causes of the low conception rates include incomplete prevention of egg loss by expulsion, embryotoxic effects of carbon dioxide or the occurrence of uterine infection during transfer. The object of this study was to investigate further the reasons for the low conception rate associated with nonsurgical egg transfers in cattle.

Three experiments were performed. Experiment 1 was designed to test whether the pregnancy rate in recipient heifers was affected by the position in the uterus at which eggs were deposited during non-surgical transfer. In Exp. 2, the effect upon egg survival of altering the uterine environment of recipients at the time of transfer was tested. The object of Exp. 3 was to determine the embryotoxicity of various potential relaxants of uterine smooth muscle.

\section{MATERIALS AND METHODS}

\section{Experiment 1}

The heifers in these studies were taken from a herd run with a vasectomized bull. The heifers were observed twice daily for service marks indicative of oestrus. Donor heifers were injected subcutaneously with 1500 to 2000 i.u. PMSG (Folligon: Organon Ltd) on Day 16 of the oestrous cycle and inseminated twice with fresh diluted semen at the ensuing oestrus. Eggs were obtained from the donor animals between Days 6 and 9 after oestrus using the surgical technique described by Rowson et al. (1969). The egg flushing and storage medium was TCM 199 with Hanks' salts (Flow Laboratories) and antibiotic (1000 i.u. penicillin and $50 \mathrm{mg}$ streptomycin $/ \mathrm{ml}$ medium).

Recipient heifers were used only if they had shown oestrus within $24 \mathrm{hr}$ of the onset of oestrus in the donor animal. In the first group of 25 heifers, a single egg was transferred into the body of the uterus by the non-surgical method described by Rowson \& Moor (1966). The 1-ml glass insemination pipette was inserted through the vagina and cervix and then as far into the body of the uterus as possible before the egg was deposited. 
In the second group which consisted of nine heifers, a flexible polyethylene tube of $4 \mathrm{~mm}$ diameter, closed at one end but with a side opening flush with the seal, was used for egg transfers. This tube was inserted into the uterus through the cervix and manipulated per rectum until it reached the tip of the uterine horn. Egg transfer was accomplished by taking up the egg in a glass pipette attached to a syringe and inserting it into the free end of the polyethylene tube. Sufficient medium was held behind the eggs to ensure that they were flushed through the tube and deposited in the tip of the uterine horn. In both groups, the uterus was inflated with carbon dioxide gas after the egg was deposited.

Following non-surgical egg transfer, the recipient heifers were again run with a vasectomized bull. Animals which had not shown oestrus by Day 35 were examined per rectum to confirm pregnancy. In the absence of facilities for keeping pregnant animals, all animals were slaughtered after the 3rd month of pregnancy. Pregnancies were confirmed from examinations of the reproductive tracts.

\section{Experiment 2}

A total of 80 heifers, maintained under the same conditions as described previously, were randomly allocated to one of three groups in which different egg transfer procedures were used. One egg was transferred with a glass insemination pipette to the body of the uterus of each of 30 heifers in the 'Control' group, as described in Exp. 1. The deposition of one egg into the body of the uterus of each of the 20 recipients in the 'Carbon dioxide' group was followed by inflation of the uterus with carbon dioxide by the technique of Rowson \& Moor (1966). In the 'Fluothane' group (30 animals), anaesthesia was induced with thiopentone sodium (Pentothal: Abbott) and maintained with an oxygen-Fluothane (I.C.I. Ltd) mixture. After each recipient had been under Fluothane anaesthesia for $10 \mathrm{~min}$, one egg was placed in the body of the uterus by the same non-surgical procedure as was used in the 'Control' group. Following egg transfer, Fluothane anaesthesia was maintained for a further 15 min and the animal was then allowed to recover.

Each of the above groups was sub-divided; eggs were transferred to one subgroup on Days 3 to 5 of the oestrous cycle, at a time when the circulating progesterone levels were increasing. Eggs were transferred to the second subgroup between Days 6 and 9 after blood progesterone concentrations had risen to maximum levels (Shemesh et al., 1971).

The recipient heifers were run with a vasectomized bull after transfer and thereafter treated in the same manner as that described for animals in Exp. 1.

\section{Experiment 3}

This study was undertaken to determine the potential direct embryotoxic effects of the carbon dioxide and Fluothane treatments used in the preceding experiments. To reduce expense, sheep were used as experimental animals. Forty Welsh Mountain ewes were used as recipients and a further nine as egg donors. The donors were injected subcutaneously with 900 to 1000 i.u. PMSG on Day 12 of the cycle and were mated with two fertile rams at oestrus.

Eggs were recovered from the donors between Days 3 and 5 of the cycle by 
the technique of Hunter et al. (1955). Single eggs were transferred to the uteri of recipient ewes which had exhibited oestrus within $24 \mathrm{hr}$ of the donors. After transfer, each recipient was subjected to one of the following four treatments. The uterus of each ewe in Group 1 was gently inflated with carbon dioxide after deposition of the egg. The gas was introduced through the transfer pipette. In Group 2, nitrogen was used instead of carbon dioxide to inflate the uterus, thereby producing a similar degree of uterine distension but without the predicted reduction in uterine $\mathrm{pH}$ associated with carbon dioxide treatment. Fluothane liquid ( $50 \mu \mathrm{l} /$ animal) was injected directly into the lumen of the uterus of sheep in Group 3, while animals in Group 4 served as controls and received no treatment after transfer of the egg.

Recipient ewes were placed with vasectomized rams in the postoperative period and the pregnant animals were allowed to lamb.

\section{RESULTS}

In Exp. 1, only $1 / 25$ heifers in which a single egg was placed in the body of the uterus became pregnant. None of the nine heifers in the second group became pregnant.

Table 1. The numbers of pregnancies in heifers after non-surgical transfer of eggs through the cervix during dioestrus and when the procedure was followed by inflation of the uterus with carbon dioxide, or carried out under Fluothane anaesthesia

\begin{tabular}{|c|c|c|c|c|c|c|c|}
\hline \multirow{2}{*}{$\begin{array}{c}\text { Transfer } \\
\text { procedure* }\end{array}$} & \multirow{2}{*}{$\begin{array}{l}\text { Day of } \\
\text { cycle }\end{array}$} & \multirow{2}{*}{$\begin{array}{l}\text { No. of } \\
\text { heifers }\end{array}$} & \multicolumn{3}{|c|}{ No. and synchrony of heifers $\dagger$} & \multirow{2}{*}{$\begin{array}{c}\text { No. of } \\
\text { pregnancies }\end{array}$} & \multirow{2}{*}{$\begin{array}{c}\text { Synchronization } \\
\text { in successful } \\
\text { transfers }\end{array}$} \\
\hline & & & Day - 1 & Day 0 & Day +1 & & \\
\hline \multirow[t]{2}{*}{ Control } & 3 to 5 & 10 & 3 & 6 & 1 & 1 & 1 at Day 0 \\
\hline & 6 to 9 & 20 & 4 & 14 & 2 & 7 & $\left\{\begin{array}{l}4 \text { at Day } 0 \\
1 \text { at Day }+1\end{array}\right.$ \\
\hline $\begin{array}{l}\text { Carbon } \\
\text { dioxide }\end{array}$ & $\begin{array}{l}3 \text { to } 5 \\
6 \text { to } 9\end{array}$ & $\begin{array}{l}10 \\
10\end{array}$ & $\begin{array}{l}3 \\
3\end{array}$ & $\begin{array}{l}7 \\
7\end{array}$ & $\begin{array}{l}0 \\
0\end{array}$ & $\begin{array}{l}0 \\
1\end{array}$ & 1 at $\overline{\mathrm{Day}} \quad 0$ \\
\hline Fluothane & $\begin{array}{l}3 \text { to } 5 \\
6 \text { to } 9\end{array}$ & $\begin{array}{l}10 \\
20\end{array}$ & $\begin{array}{l}4 \\
0\end{array}$ & $\begin{array}{r}6 \\
18\end{array}$ & $\begin{array}{l}0 \\
2\end{array}$ & $\begin{array}{l}1 \\
8\end{array}$ & 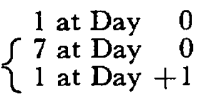 \\
\hline Total & & 80 & 17 & 58 & 5 & 18 & \\
\hline
\end{tabular}

\footnotetext{
* See text for details.

$\dagger$ Synchrony was related to the days by which oestrus in the recipient preceded $(+)$ or succeeded (-) oestrus in the donor.
}

The results obtained in Exp. 2 are summarized in Table 1. When nonsurgical transfers were made to heifers early in dioestrus (Days 3 to 5), only one pregnancy resulted in each of the 'Control' and Fluothane-treated groups. A considerably better conception rate was obtained in each of these groups when transfers were made later in dioestrus (Days 6 to 9). Seven of the 20 'Control' heifers and 8/20 heifers treated with Fluothane became pregnant. This improvement in conception rate when the transfer operation was performed later in 
dioestrus was not statistically significant in either group. There was no significant difference between the proportions of 'Control' and Fluothanetreated heifers which became pregnant. When the results for early and late transfers in both groups were pooled, the advantage in favour of late transfer approached significance $\left(\chi^{2}=3 \cdot 704 ; 0 \cdot 05<P<0 \cdot 10\right)$.

Inflation of the uterus with carbon dioxide following placement of the egg gave poor results with both early and late transfers. The only pregnancy obtained was after late transfer.

A consideration of the numbers of animals which conceived after late transfer according to the day on which the transfer was actually done showed that $4 / 12$, $8 / 16,3 / 13$ and $1 / 9$ animals receiving eggs on Days $6,7,8$ or 9 , respectively, became pregnant. Discarding the results for the carbon dioxide-treated recipients further emphasized the conception rate achieved on Days 6 and 7, with $4 / 8,8 / 14,3 / 11$ and $0 / 7$ animals becoming pregnant on Days $6,7,8$ or 9 , respectively.

The majority of non-pregnant heifers returned to oestrus within 18 to 25 days of their preoperative oestrus (43/62). Eight more were observed in oestrus about the time that the second postoperative oestrus was predicted. Of the remaining heifers, five had returned to oestrus by Day 65 and the rest (six) were disposed of after determining that they were not pregnant when reexamined per rectum.

The relatively poor results which were obtained in heifers in Exp. 2 when nonsurgical egg transfer was followed by inflation of the uterus with carbon dioxide could not be ascribed to embryotoxic effects of the gas since uterine inflation with carbon dioxide or nitrogen did not affect the number of ewes which became pregnant in Exp. 3;6/10 controls, 6/10 treated with carbon dioxide, $5 / 10$ treated with nitrogen and $0 / 10$ treated with Fluothane. No pregnancies resulted when $50 \mu \mathrm{l}$ liquid Fluothane were introduced into the uteri of ewes. Embryo death probably occurred before Day 12 since all except one of the ewes in which pregnancy failed returned to oestrus at the expected time for normal cyclic animals.

\section{DISCUSSION}

The most interesting and encouraging result from these experiments was the improved conception rate when non-surgical transfers in cattle were made later (Days 6 to 9) rather than earlier (Days 3 to 5) in dioestrus. While the number of animals available was too few to obtain statistical significance $(0.05<P<0 \cdot 10)$ in this comparison, the indication that the stage of the cycle at which nonsurgical transfers were attempted was critical and was sufficient to promote further endeavours in this field.

Achievement of seven and eight pregnancies in 20 heifers in the late 'Control' and 'Fluothane anaesthesia' groups, respectively, was better than any results previously reported using the transcervical route. With techniques comparable to that used in our early 'Control' group, no pregnancies were obtained in eight, twelve and eleven cows by Dowling (1949), Rowson (1951) and Avery et al. (1962), respectively. Dziuk et al. (1958) reported 1/9 animals pregnant 
and Mutter et al. (1964) reported one pregnancy from an unspecified number of transfers. In view of these consistent failures in the past, our success when the transfers were performed late in dioestrus demonstrates the importance of the stage of cycle in determining the outcome of non-surgical transfers.

Our failure to obtain pregnancies when the uterus was inflated with carbon dioxide in both Exp. 1 (1/34 heifers pregnant) and Exp. 2 (0/10 and 1/10 heifers pregnant in the early and late groups, respectively) is puzzling in view of some previous success with the technique. Rowson \& Moor (1966) reported 3/14 pregnancies in heifers, Rowson et al. (1969) 4/20 and Vincent et al. (1969) 2/15 pregnant. Our results in Exps 1 and 2 indicate the dubious value of the procedure. The failure of the carbon dioxide technique in conjunction with late transfers while good results were obtained in the 'Control' heifers and those treated with Fluothane is consistent with a deleterious effect of carbon dioxide. There was, however, no indication that carbon dioxide was embryotoxic in ewes in Exp. 3, and Vincent et al. (1969) were unable to show an effect of carbon dioxide in naturally pregnant cows. The blastocysts transferred in the late groups of Exp. 2 may have been more susceptible to the effects of carbon dioxide than the earlier embryonic stages transferred to ewes in Exp. 3 or in previous experiments in the cow.

Fluothane has been shown to produce relaxation of the human myometrium (Sadove \& Wallace, 1962; McDonald-Gibson, 1969). Palpation of the bovine uterus during Fluothane anaesthesia indicates that a similar effect is produced in cattle. An absence of embryotoxic effects with liquid Fluothane introduced directly into the uterus in Exp. 3 would have been an indication for its potential use locally to control uterine motility during non-surgical egg transfer in cattle. The quantity of Fluothane liquid used was chosen arbitrarily, and based on the approximate weights of the ewe's uterus and the concentrations of Fluothane found in body tissues during anaesthesia (Sadove \& Wallace, 1962).

Despite its relaxant effect on the uterus, the use of Fluothane did not confer any advantage over the 'Control' procedure when early or late transfers were done in heifers in Exp. 2. The lack of effectiveness of this relatively potent uterine relaxant argues against the likelihood that a relaxing or anaesthetic effect from carbon dioxide admitted into the uterus could hinder the expulsion of non-surgically transferred eggs, as was proposed by Rowson \& Moor (1966). Barring chance, the mechanism by which carbon dioxide assisted the previous successful non-surgical transfers cited earlier may have been mechanical, through distension of the uterine lumen. The absence of deleterious effects of carbon dioxide and nitrogen in the uterus of the ewe in Exp. 3 suggests that nitrogen might be substituted experimentally as an aid to non-surgical transfers in the cow.

Without giving undue emphasis at this stage, the trend in Exp. 2 for pregnancies to occur in heifers which received eggs on Days 6 and 7 should receive further attention. This may be an indication that an optimum time exists for attempting non-surgical transfers. The normal returns to oestrus in the experimental heifers which failed to remain pregnant and the absence of any indication that uterine infections were induced, even when transfers were 
performed in mid-cycle, is also worthy of note. Failure in this respect would seriously hinder future practical applications of non-surgical egg transfer in cattle. An explanation for the success of late non-surgical egg transfers depends on further experiment. The reduced motility of the uterus when there are high levels of circulating progesterone is likely to be a factor, but the blastocyst too may be less susceptible to explusion from the uterus than earlier stages in which the zona pellucida is intact.

\section{REFERENCES}

Avery, T.L., Fahning, M.L., Pursel, V.G. \& Graham, E.F. (1962) Investigations associated with the transplantation of bovine ova. IV. Transplantation of ova. F. Reprod. Fert. 3, 229-238.

BENNETT, J.P. \& Rowson, L.E.A. (1961) The use of radioactive artificial eggs in studies of egg transfer and transport in the female reproductive tract. Proc. 4th Int. Congr. Anim. Reprod. \&O A.I., The Hague 2, 360-366.

Dowl.ING, D.F. (1949) Problems of the transplantation of fertilized ova. F. agric. Sci., Camb. 39, 374-396.

Dziuk, P.J., Donker, J.D., Nichols, J.R. \& Petersen, W.E. (1958) Problems associated with the transfer of ova between cattle Bull. Minn, agric. Exp. Stn 222, 1-75.

HARPer, M.J.K., BennetT, J.P. \& Rowson, L.E.A. (1961) A possible explanation for the failure of non-surgical ovum transfers in the cow. Nature, Lond. 190, 789-790.

Hunter, G.L., Adams, C.E. \& Rowson, L.E. (1955) Inter-breed ovum transfer in sheep. F. agric. Sci., Camb. 46, 143-149.

MaDonald-Grbson, W.J. (1969) The influence of halothane (fluothane) on isolated human uterine muscle. F. Obstet. Gynaec. Br. Commonw. 76, 362-365.

Mutter, L.R., Graden, A.P. \& Olds, D. (1964) Successful non-surgical bovine embryo transfer. A.I. Digest 12, 3.

Rowson, L.E. (1951) Methods of inducing multiple ovulation in cattle. F. Endocr. 7, 260-270.

Rowson, L.E.A. \& Moor, R.M. (1966) Non-surgical transfer of cow eggs. F. Reprod. Fert. 11, 311-312.

Rowson, L.E.A., BENNETT, J.P. \& HARPeR, M.J.K. (1964) The problem of non-surgical egg transfer to the cow uterus. Vet. Rec. 76, 21-23.

Rowson, L.E.A., Moor, R.M. \& LAwson, R.A.S. (1969) Fertility following egg transfer in the cow: effect of method, medium and synchronization of oestrus. F. Reprod. Fert. 18, 517-523.

Rowson, L.E.A., LAwson, R.A.S. \& Moor, R.M. (1971) Production of twins in cattle by egg transfer. 7. Reprod. Fert. 25, 261-268.

Sadove, M.S. \& Wallace, V.E. (1962) Halothane, pp. 52, 95 and Abstr. Davis Publications, New York.

Shemesh, M., Lindner, H.R. \& Ayalon, N. (1971) Competitive protein-binding assay of progesterone in bovine jugular venous plasma during the oestrous cycle. J. Reprod. Fert. 26, 167-174.

Sugre, T. (1965) Successful transfer of a fertilized bovine egg by non-surgical techniques. J. Reprod. Fert. 10, 197-201.

Vincent, C.K., Mills, A.C. \& Rundeld, J.W. (1969) Non-surgical transfer of embryos in beef cattle. 7. Anim. Sci. 28, 147, Abstr. 